cytotoxic treatment. Early diagnosis and vigorous treatment of respiratory complications may help to avert chronic infection and deaths in remission.

We thank Professor N R Butler and Dr M G Mott, Bristol Children's Hospital, and Dr J N Montgomery and Dr M K Strelling, Plymouth General Hospital, for their helpful advice and permission to publish details of children under their care; and Dr M Silverman for constructive criticisms.

\section{References}

1 Simone, J V, Holland, E, and Johnson, W, Blood, 1972, 39, 759.

2 Hersh, E M, et al, fournal of the American Medical Association, 1965, 193, 99.
3 Field, C E, Archives of Disease in Childhood, 1969, 44, 551.

${ }^{4}$ British Medical fournal, 1975, 2, 604.

5 Simone, J V, Advances in Pediatrics, 1972, 19, 13.

${ }^{6}$ Gold, D W, et al, British Medical fournal, 1975, 2, 166.

- Campbell, A C, et al, British Medical fournal, 1973, 2, 385.

${ }^{4}$ Graham-Pole, J, et al, British Medical fournal, 1975, 2, 467.

Medical Research Council, British Medical fournal, 1975, 3, 563.

10 Stiehm, E R, and Fulginiti, V A, Immunologic Disorders in Infants and Children. Philadelphia, Saunders, 1973.

1 Lawlor, G J, et al, The fournal of Pediatrics, 1974, 84, 183.

12 Borella, L, and Webster, R G, Cancer Research, 1971, 31, 420.

${ }^{13}$ Co-operative Study, Fournal of the American Medical Association, 1969, 207, 923.

14 Trier, J S, Gastroenterology, 1962, 42, 295.

${ }^{15}$ Roenigk, H H, et al, Archives of Dermatology, 1971, 103, 250.

${ }^{16}$ McInerney, D P, and Bullimore, J, British fournal of Radiology, 1977, 50, 224.

(Accepted 4 fuly 1977)

\title{
Vitamin D supplements and 25-hydroxy vitamin D concentrations in the elderly
}

\author{
W J MACLENNAN, JUDITH C HAMILTON
}

British Medical fournal, 1977, 2, 859-861

\section{Summary}

Serial 25-hydroxy vitamin D (25-OHD) concentrations were measured in long-stay geriatric patients treated with vitamin $D$. Comparison between a treatment and a control group showed that a daily dose of 500 IU vitamin $D$ produced a significant increase in 25-OHD levels by two months. The supplement had a striking effect when the initial 25-OHD level was low and very little effect when it was high. 25-OHD levels in subjects on 2000 IU vitamin $D$ daily were only marginally higher than those in subjects on $500 \mathrm{IU}$.

A dose of 500 IU vitamin $D$ daily should therefore produce adequate blood 25-OHD concentrations in most old people, and probably prevent most cases of osteomalacia in the elderly-though a large-scale study is needed to confirm this.

\section{Introduction}

Many sick old people have osteomalacia. " Even more have low plasma 25-hydroxy vitamin D (25-OHD) concentrations. ${ }^{34}$ The simplest preventive approach might be to give vitamin supplements, but Corless et $\mathrm{al}^{3}$ found that a group of patients in a long-stay geriatric hospital had low 25-OHD levels despite the fact that they had been on a long course of vitamin $D$ supplements. We report the effects of varying doses of vitamin $\mathrm{D}$ on $25-\mathrm{OHD}$ concentrations in sick elderly patients.

\section{Subjects and methods}

All subjects were in a long-stay geriatric unit and were aged 68 to

Faculty of Medicine, University of Southampton, Southampton SO9 4XY

W J MACLENNAN, MD, MRCP, senior lecturer in geriatric medicine JUDITH C HAMILTON, MSC, biochemist
92 years. Plasma 25-OHD concentrations were estimated using the method described by Belsey et al. ${ }^{5}$ The study was in three parts.

Part 1-In July 1976 eight subjects with plasma 25-OHD concentrations of under $15 \mathrm{nmol} / 1(6 \mathrm{ng} / \mathrm{ml})$ were given $500 \mathrm{IU}$ of vitamin $\mathrm{D}$ daily as one tablet of calcium and vitamin $\mathrm{D} B P C$. 25-OHD concentrations were estimated on plasma samples collected each week for one month.

Part 2-In August 197612 subjects with 25-OHD concentrations of under $30 \mathrm{nmol} / 1(12 \mathrm{ng} / \mathrm{ml})$ were given $2000 \mathrm{IU}$ of vitamin D daily, again as calcium and vitamin D tablets. Plasma 25-OHD concentrations were measured at each week for one month and again at the end of six months.

Part 3-In November 197630 patients with plasma 25-OHD concentrations of 5 to $57 \mathrm{nmol} / 1$ ( 2 to $22.8 \mathrm{ng} / \mathrm{ml}$ ) were divided at random into two groups. Fifteen subjects were given $500 \mathrm{IU}$ of vitamin $\mathrm{D}$ daily as calcium and vitamin $\mathrm{D}$ tablets. The rest had no treatment. Plasma 25-OHD concentrations were measured every month for four months.

\section{Results}

Part 1-One of the subjects was discharged from hospital. There was little change in the mean plasma 25-OHD concentrations of the remaining subjects (fig 1 ).

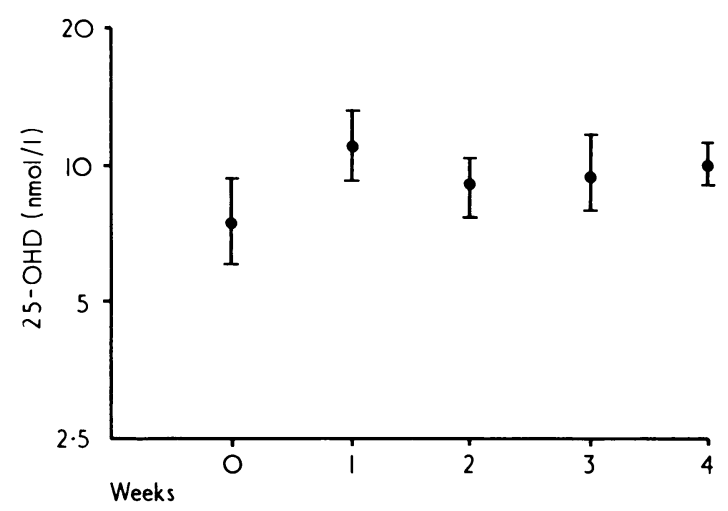

FIG $1-\log _{10}$ mean ( \pm SE of mean) $25-$ OHD concentrations in subjects taking 500 IU vitamin D daily.

Conversion: SI to traditional units-25-OHD: $1 \mathrm{nmol} / 1 \approx$ $0.4 \mathrm{ng} / \mathrm{ml}$ 
Part 2-One subject was discharged, another died, and a third had difficulty in taking tablets. Mean plasma 25-OHD concentrations in the other nine rose steadily over the four weeks (fig 2). One of the subjects subsequently died. The mean $25-\mathrm{OHD}$ concentrations of the remainder rose from $14.5 \mathrm{nmol} / 1(5.8 \mathrm{ng} / \mathrm{ml})$ in August 1976 to $81.3 \mathrm{nmol} / 1(32.5 \mathrm{ng} / \mathrm{ml})$ in February $1977,95 \%$ confidence limits for the final assay being $56 \cdot 2-117 \cdot 5 \mathrm{nmol} / 1(22 \cdot 5-47 \mathrm{ng} / \mathrm{ml})$.

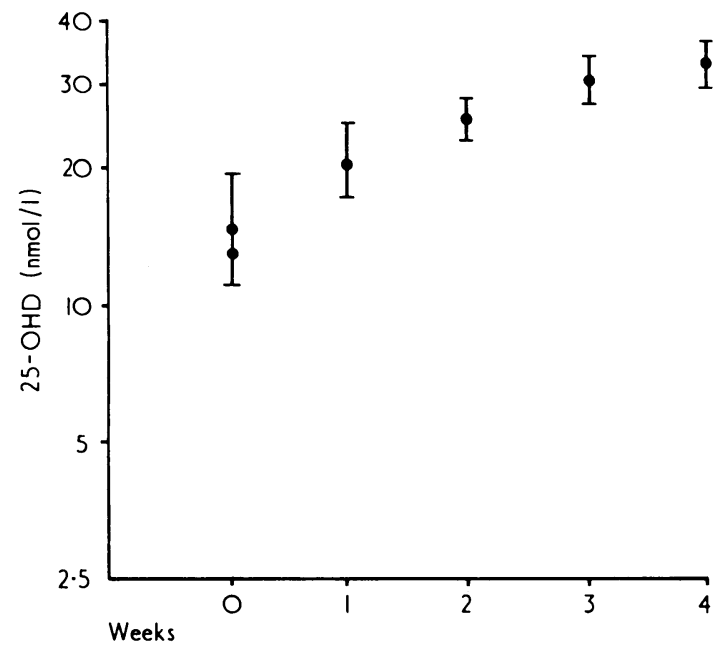

FIG 2- $\log _{10}$ mean ( $t$ SE of mean) 25-OHD concentrations in subjects taking 2000 IU vitamin D daily.

Part 3-There were three deaths and one discharge, and technical difficulties made it impossible to collect a complete set of samples in another three subjects. This left 11 subjects on supplements and 12 in the control group. Mean 25-OHD concentrations varied considerably month by month in both groups (fig 3). Significances of differences at $0,1,2,3$, and 4 months were $0.7>\mathbf{P}>0.6,0.2>\mathbf{P}>0.1$, $0.05>\mathbf{P}>0.02,0.02>\mathbf{P}>0.01$, and $0.01>\mathbf{P}>0.001$ respectively. In the treated group the mean 25-OHD levels rose over four months from 22.3 to $52.5 \mathrm{nmol} / 1(8.9$ to $21 \mathrm{ng} / \mathrm{ml})$. The subjects were then divided into those with $25-\mathrm{OHD}$ concentrations less than $20 \mathrm{nmol} / \mathrm{l}$ $(8 \mathrm{ng} / \mathrm{ml}$ ) (five on treatment and six controls) and those with concentrations of $20 \mathrm{nmol} / 1$ and over (six on treatment and six controls).

In the first group significances of differences between treated subjects and controls at $0,1,2,3$, and 4 months were $0.3>\mathbf{P}>0.2$ $0.02>P>0.01,0.02>P>0.01,0.01>P>0.001$, and $0.01>P>0.001$

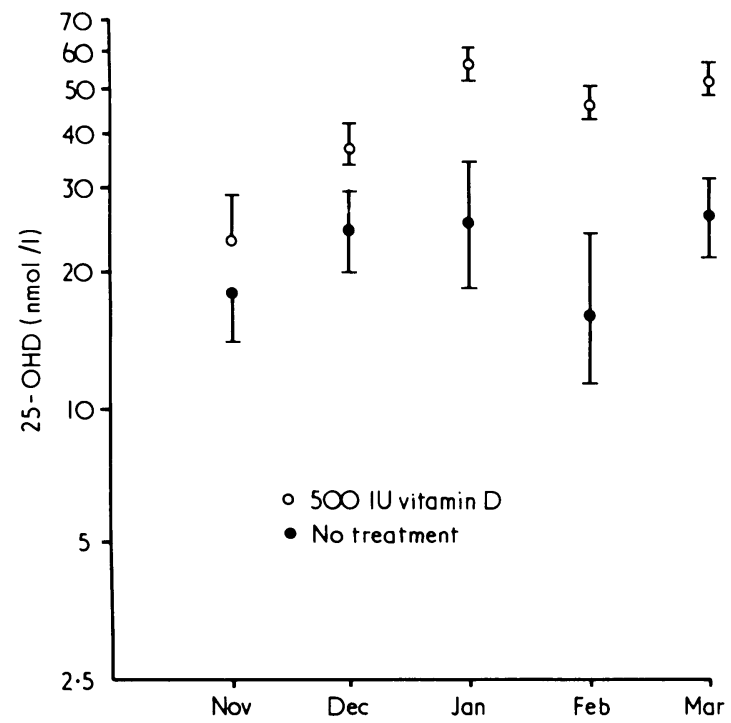

FIG 3- $\log _{10}$ mean ( \pm SE of mean) $25-O H D$ concentrations in subjects taking $500 \mathrm{IU}$ vitamin D daily compared with those in subjects not taking vitamin $\mathrm{D}$.

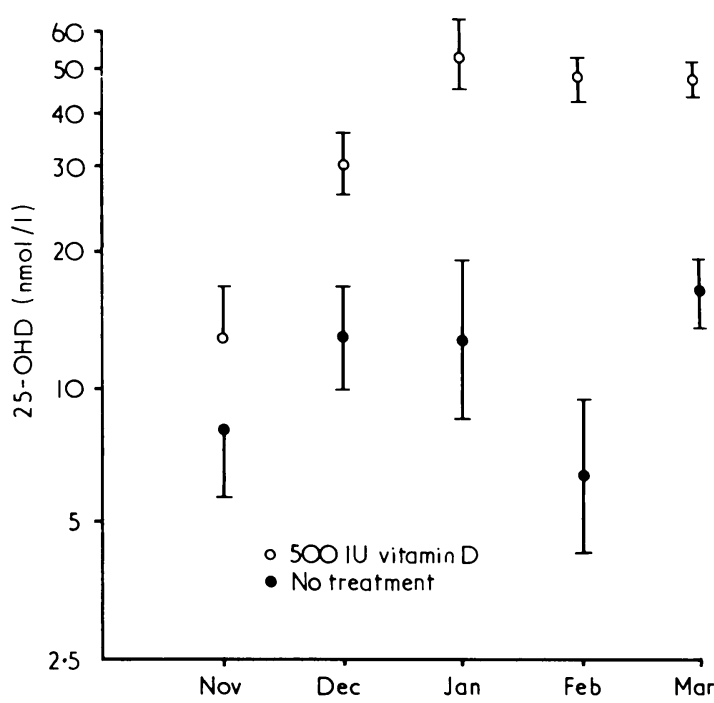

FIG 4- $\log _{10}$ mean ( \pm SE of mean) 25-OHD concentration in subjects with initial concentrations of under $20 \mathrm{nmol} / \mathrm{l}$ according to whether or not they received 500 IU vitamin D daily.

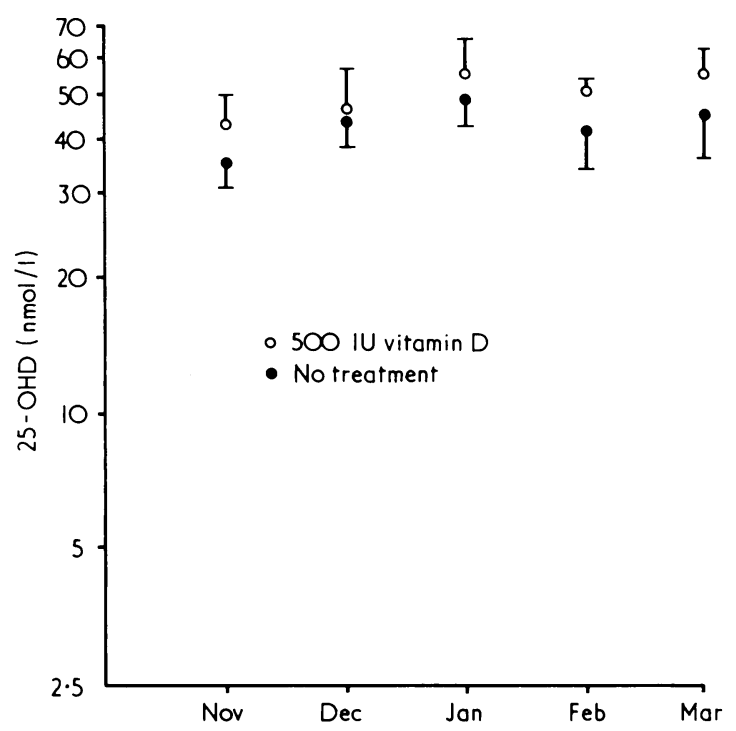

FIG 5 - $\log _{10}$ mean ( \pm SE of mean) $25-\mathrm{OHD}$ concentrations in subjects with initial concentrations of over $20 \mathrm{nmol} / 1$ according to whether or not they received 500 IU vitamin D daily.

respectively (fig 4). In the second group there was very little difference in 25-OHD concentrations between controls and those on treatment (fig 5).

\section{Discussion}

Factors other than diet may influence vitamin D metabolism. Thus 25-OHD concentrations show a striking seasonal variation, which suggests that sunlight exposure is important. ${ }^{6} 7$ Age and disease might also reduce 25-OHD levels by interfering with vitamin $\mathrm{D}$ hydroxylation. Review of our control group shows that month-to-month variation could be enough to mask the effects of vitamin supplements. This might account in part for the differences between our findings and those of Corless et al. ${ }^{3}$ It might also explain why $500 \mathrm{IU}$ of vitamin $\mathrm{D}$ daily produced little change in the 25-OHD concentrations of a group treated in July but had a more striking effect in subjects treated in November. 
The response to vitamin $\mathrm{D}$ also varied with the initial concentrations of 25-OHD. When subjects were divided into groups with $25-\mathrm{OHD}$ concentrations below and above $20(8 \mathrm{ng} / \mathrm{ml})$, 25-OHD concentrations rose steeply in those with low initial concentrations, while subjects starting with higher values showed only marginal changes. These findings support the view that vitamin D hydroxylation is regulated by product inhibition." Once physiological levels of 25-OHD are reached further vitamin $\mathrm{D}$ is less likely to be converted into active metabolites.

Consideration should be given to the dose of vitamin $\mathrm{D}$ necessary to correct deficiency in patients with low 25-OHD levels. Two months after the start of treatment with $500 \mathrm{IU}$ of vitamin $\mathrm{D}$ elderly subjects with initial 25-OHD concentrations of under $20 \mathrm{nmol} / 1(8 \mathrm{ng} / \mathrm{ml})$ had a mean $25-O H D$ concentration of $52.5 \mathrm{nmol} / 1(21 \mathrm{ng} / \mathrm{ml})$ with $95^{\circ}$ " confidence limits of 26.3 to $104.7 \mathrm{nmol} / 1(10.5$ to $41.9 \mathrm{ng} / \mathrm{ml})$. These values are almost identical to the $95^{\circ}$ " confidence limits of 25 to $100 \mathrm{nmol} / 1$ (10 to $40 \mathrm{ng} / \mathrm{ml}$ ) found in healthy young adults. ${ }^{6}$ It would thus appear that on a regular daily dose of $500 \mathrm{IU}$ of vitamin $\mathrm{D}$ most old people would avoid the dangers of vitamin $\mathrm{D}$ deficiency.

The response of subjects to 2000 IU of vitamin D daily over one month was greater than that recorded for those on $500 \mathrm{IU}$ in July but almost identical to that found for those on $500 \mathrm{IU}$ in November. This further illustrates the difficulties of comparing 25-OHD concentrations in samples taken at different times. It is more valid to note that in February the mean 25-OHD concentrations of subjects on $500 \mathrm{IU}$ of vitamin $\mathrm{D}$ daily for four months and those on 2000 IU daily for six months were $52.5 \mathrm{nmol} / 1$ and $81.3 \mathrm{nmol} / 1(21.2$ and $32.5 \mathrm{ng} / \mathrm{ml})$ respectively. Thus a fourfold increase in dosage over a longer period of time had produced only a marginally higher blood concentration. This is further evidence of $25-\mathrm{OHD}$ concentrations being controlled by feedback regulation.

A daily dose of 500 IU of vitamin D seems to produce adequate concentrations of 25-OHD in most old people. The use of larger doses in conditions other than renal disease, malabsorption, or overt metabolic bone disease does not seem justified. A large-scale study is now required to assess whether controlling 25-OHD concentrations would have any effect on the incidence and consequences of metabolic bone disease in old age.

\section{References}

${ }^{1}$ Anderson, I, et al, Scottish Medical fournal, 1966, 11, 429.

2 Chalmers, J, et al, fournal of Bone and foint Surgery, 1967, 49B, 403.

${ }^{3}$ Corless, D, et al, Lancet, 1975, 1, 1404

${ }^{4}$ Nayal, A S, et al, submitted for publication.

${ }^{5}$ Belsey, R E, De Luca, H F, and Potts, J T, fournal of Clinical Endocrinology and Metabolism, 1974, 38, 1046.

- Stamp, T C B, and Round, J M, Nature, 1974, 247, 563.

' McLaughlin, M, et al, Lancet, 1974, 1, 536.

${ }^{8}$ Haddad, J G, and Stamp, T C B, American fournal of Medicine, 1974, 57, 57.

(Accepted 5 August 1977)

\section{Summary}

A five-year therapeutic trial of carbohydrate restriction with or without phenformin $(50 \mathrm{mg} /$ day) was performed in men with borderline diabetes. The aim of treatment was to diminish the enhanced risk of cardiovascular disease and deterioration of glucose tolerance. Cardiovascular morbidity and mortality were not significantly affected by any form of treatment, alone or in combination. The predominant risk factor for cardiovascular morbidity and mortality and for overall mortality was the initial blood pressure level. The baseline plasma cholesterol concentration significantly predicted the onset of intermittent claudication.

One implication of the results is that hypotensive

\section{Guy's Hospital, London SE1 9RT}

R J JARRETT, MD, MFCM, senior lecturer, department of community medicine

H KEEN, MD, FRCP, professor of human metabolism

J H FULLER, MA, MRCP, honorary lecturer, department of medicine (now senior research fellow, Department of Medical Statistics and Epidemiology, London School of Hygiene and Tropical Medicine, London WC1) M MCCARTNEY, MSC, research associate, unit for metabolic medicine treatment, supplemented when necessary with nypolipidaemic treatment, may be more effective in preventing the progression of arterial disease in people with mild to moderate glucose intolerance than conventional antidiabetic therapy.

\section{Introduction}

People with slightly impaired glucose tolerance, whether or not diagnosed formally as diabetic, have an increased risk of developing a more manifest diabetes-with fasting hyperglycaemia 1 and coronary heart disease. " Such "borderline diabetics" thus constitute a high-risk group in whom the influence of treatment on metabolic and vascular phenomena can be systematically and ethically studied. Previous studies have suggested that sulphonylurea treatment might be beneficial, ${ }^{34}$ but the differences from placebo-treated controls have not been large and any conclusions must be guarded. The large population of male civil servants submitted to systematic blood sugar and cardiovascular screening in $1968-70^{5}$ provided us with the opportunity to identify a new group of borderline diabetics and examine the effects of treatment in a rather more homogeneous population than in our previous study in Bedford.

The basic design of the study was to compare the effects of advice to restrict carbohydrate consumption to $120 \mathrm{~g}$ /day with advice simply to reduce sucrose intake. Within each of these two diet groups the effect of treatment with a low dose of phenformin 